\title{
Nonsusceptibility to otitis media of the laboratory gerbil, Meriones unguiculatus
}

\author{
LARRY W. MEANS, HAL J. DANIEL, LILLIAN H. JORDAN, and PATRICIA J. LOESCHE \\ East Carolina University, Greenville, North Carolina 27834
}

\begin{abstract}
Mongolian gerbils housed with laboratory rats under conditions designed to maximize the transmission of otitis media were found at necropsy to be free of this middle ear disease, while the rats were found to have an $83 \%$ incidence.
\end{abstract}

Otitis media, or middle ear infection, has been a disturbing problem to animal researchers using the laboratory rat for some time. McCordock and Congdon (1924) and Nelson and Gowen (1930) found otitis media in some colonies to be as high as $50 \%$, with an increasing incidence as a function of age. A recent study by Daniel et al. (1973) also found the frequency of otitis media in Long-Evans rats to increase with age of subject and to be higher in females as well as in animals subjected to stereotaxic brain lesions. Based upon these findings, the authors suggested precautions to experimenters using rats in auditory studies.

While there is less than total agreement on the organism that causes otitis media, Lindsey, Baker, Overcash, Cassell, and Hunt (1971) concluded from a study of the etiologic agents of otitis media in laboratory rats that the organism responsible for the disease is Mycoplasma pulmonis.

The Mongolian gerbil (Meriones unguiculatus), with its characteristic docility, curiosity, and cleanliness has been increasingly used in the laboratory (Rich, 1968; Schwentker, 1963). However, it was not until 1966 that studies of the rodent's peripheral auditory mechanism demonstrated its potential for behavioral auditory research. Finck and Sofouglu (1966) reported the gerbil's range of frequency response in a cochlear microphonic study to be between $200 \mathrm{~Hz}$ and $30,000 \mathrm{~Hz}$, with the best auditory sensitivity range between $3,000 \mathrm{~Hz}$ and $5,000 \mathrm{~Hz}$. The gerbil's suitability as a behavioral subject has been previously described (Thiessen, 1968; Walters, Pearl, \& Rogers, 1963), and its preferential use over the laboratory rat for auditory research was recently supported by our unpublished data in which comparative anatomical studies of the vertebrate auditory mechanism yielded not one case of otitis media in this species $(\mathrm{N}=30)$. The only known findings of otitis media in gerbils were made by D. M. Lay (personal communication) in different species $(M$. Libycus and $M$. crassus) ranging from 25 to 50 months

Reprint requests should be sent to Hal J. Daniel, Department of Anatomy, East Carolina University, School of Medicine, Greenville, North Carolina 27834. of age. No epidemiological data on the overall incidence of otitis media in these species is available, however.

As research animals are usually housed in a single facility, a study was undertaken to compare the incidence of otitis media in gerbils and rats raised under conditions maximizing disease transmission. It was anticipated that the results of this study would provide further evidence of the desirability of using the Mongolian gerbil in auditory research.

\section{METHOD}

\section{Subjects}

Fifty-two Mongolian gerbils (Meriones unguiculatus), ranging in age from 6 weeks to 6 months at the beginning of the experiment, and 13 Long-Evans rats, all exceeding 6 months in age at the beginning of the experiment, were used as subjects. Twenty-six of the gerbils, matched in age and sex with the remaining 26 , were immediately sacrificed and examined to determine the incidence of otitis media at the time of delivery to the laboratory. The remaining animals were maintained at a mean temperature of $25^{\circ} \mathrm{C}$ and on a 16 -h light/8-h dark cycle. They had water and lab chow available continuously.

\section{Housing Procedures}

The rats and gerbils were housed in the same rack of cages in an isolated portion of one room of the animal colony under conditions designed to maximize transmission of disease both within and across species. Rats were housed individually, and gerbils were housed in pairs of the same sex in alternate $12 \times 24 \times 18 \mathrm{~cm}$ metal cages. Each cage was equipped with a water bottle and contained a small wooden "chewing" block that remained with the cage for the duration of the experiment. The cages were not washed, and the water bottles were washed only three times during the 6 months that the animals were maintained. The animals were rotated among successive cages once each week, with the water bottle and "chewing" block staying in the same cage. Thus, each week during the course of the study, each pair of gerbils was moved into a dirty cage that had been occupied the week before by a rat, while the rat was moved into a cage previously occupied by a pair of gerbils.

\section{Middle Ear Examination Procedures}

All 52 gerbils and 13 rats were sacrificed and examined for otitis media using our previously described procedure (Daniel et al., 1973) which involved sacrificing with chloroform, decaptiating, removing the mandible, and exposing the tympanic bullae by excising the surrounding fasciae. Drilling to expose the middle ear cavity was followed by observations of the occurrence of any infection. 


\section{RESULTS AND DISCUSSION}

None of the 26 gerbils that were sacrificed and examined upon being received from the supplier were found to have otitis media. Also, of 24 gerbils maintained in the laboratory for 6 months, none were found to be infected. Two gerbils died before the 6-month maintenance period was complete, and both of these animals were found to be free of otitis media. Thus no gerbil, with or without exposure to the conditions designed to maximize transmission of disease, was found to have otitis media.

Of the 13 rats included in the study, 8 were found to have bilateral infections and 2 to have unilateral infections. Two rats were found to be free of otitis media, and one rat that died before completion of the study was not examined. Thus, 10 of the 12 rats maintained under the high-transmission conditions were found to have otitis media. A $\chi^{2}$ test based on the incidence and nonincidence of otitis media in the gerbils and rats was found to be highly significant $\left(\chi^{2}=27.73\right.$, $\mathrm{p}<.001)$.

The $83 \%$ incidence of otitis media in the rats again points to their extreme susceptibility to the disease, especially when normally clean laboratory conditions are not maintained. The high incidence among the rats also clearly reveals that the conditions were adequate to transmit the disease and that the gerbils were exposed to the disease-producing organisms.

The lack of susceptibility of the gerbil to otitis media suggests its use in auditory research. In addition, the previously mentioned wide auditory sensitivity range for gerbils (Finck \& Sofouglu, 1966) is superior to that of other small rodents such as the rat (Crowley,
Hepp-Raymond, Tabowitz, \& Palin; Gourevitch \& Hack, 1966), the hamster (Finck \& Houberman, 1965), as well as the mouse (Mikaelian, Alford, \& Ruben, 1965).

These data deserve consideration by experimenters when evaluating small animals for use in behavioral auditory research.

\section{REFERENCES}

Crowley, D. E., Hepp-Raymond, M-C, Tabowitz, D., \& Palin, J. Cochlear potentials in the albino rat. Journal of Auditory Research, 1965, 5, 307-316.

Daniel, H. J., Means, L. W., Dressel, M. E., \& Loesche, P. J. Otitis media in laboratory rats. Physiological Psychology, 1973, 1, 7-8.

Finck, A., \& Houberman, M. Electrophysiological determination of the auditory sensitivity curve of the golden hamster. Abstract of Eastern Psychological Association, 1965, 104.

Finck, A., \& Sofouglu, M. Auditory sensitivity of the Mongolian gerbil. Journal of Auditory Research, 1966, 6, 313-319.

Gourevitch, G., \& Hack, M. H. Audibility in the rat. Journal of Comparative and Physiological Psychology, 1966, 6, 289-291.

Lindsey, J. R., Baker, H. J., Overcash, R. G., Cassell, G. H., \& Hunt, C. E. Murine chronic respiratory disease. American Journal of Pathology, 1971, 64, 675-707.

McCordock, H. A., \& Congdon, D. Suppurative otitis media of the albino rat. Proceedings from the Society of Experimental Biological Medicine, 1924, 22, 150-154.

Midaelian, D., Alford, B. R., \& Ruben, R. J. Cochlear potentials and VIII nerve potentials in normal and genetically deaf mice. Annals of Otology, Rhinology and Laryngology, 1965, 74, 146-157.

Nelson, J. B., \& Gowen, J. W. The incidence of middle ear infection and pneumonia in albino rats at different ages. Journal of Infectious Diseases, 1930, 46, 53-63.

Rich, S. T. The Mongolian gerbil in research. Laboratory Animal Care, 1968, 18, 235-243.

Schwentker, V. The gerbil, a new laboratory animal. Illinois Veterinarian, 1963, 6, 5-9.

Thiessen, D. D. The roots of territorial marking in the Mongolian gerbil: A problem of species-common topography. Behavioral Research Methods \& Instrumentation, 1968, 1, 70-76.

Walters, G. C., Pearl, J., \& Rogers, J. The gerbil as a subject in behavioral research. Psychological Reports, 1963, 12, 315-318.

(Received for publication February 24, 1975; revision accepted March 26, 1975.) 